THURSDAY, DECEMBER 8, I88I

\section{SMCKE-ABATEMENT EXHIBITION}

$\mathrm{O}^{\mathrm{N}}$ the 3oth ult. an exhibition was opened at South Kensington of appliances intended to prevent excessive production of smoke in household grates and in the furnaces and boilers of manufactories, and thus to remove from the fogs of great cities, and especially of London, one of their most offensive constituents, and that which is most potent in darkening the cities over which they spread themselves. The Exhibition is described as "international"; that title is, however, often given on rather a slender basis; and from what we can at present see, the main exhibits are British, although a few interesting objects are sent from Germany, Canada, and France.

The origin of the Committee, which has for the last eight monihs systematically endeavoured to direct the minds of Londoners to the question of bringing into practical use some means of lessening the smokiness of London, if not rendering London smokeless, is described in the official Report as follows; and as it may be hoped that this Exhibition is only the beginning of a movement of which, with the aid of perseverance, energy, and scientific ingenuity, mu ch may be expected, it is interesting to place the history of the movement upon record.

"The subject of the abatement of smoke, with the view of purifying the atmosphere of London and lessening the deleterious character of London fogs, has been vigorously taken up by the National Health Society during the past year. In the spring of 1880 the subject was brought under the notice of the Committee by $\mathrm{Mr}$. Ernest Hart, the Chairman of Council, as one which he was desirous of taking up actively, with the co-operation of the Committee, and he was requested to take steps to bring the question into a practical form for further proceeding. With this view Mr. Hart placed himself in communication with Prof. Chandler Roberts, F.R.S., Professor of Metallurgy at the School of Mines and Chemist to the Mint, who undertook to make an examination of existing methods of combustion of coal in household grates and in furnaces. Further steps were taken to obtain details of the existing apparatus in use in different parts of the kingdom, and a considerable collection of documents was made, which have been placed at the disposal of the Committee subsequently formed. In July Mr. Hart learned from Miss Octavia Hill, the Treasurer of the Kyrle Society, that that Society was contemplating some action in the like direction, and it was arranged between Miss Hill and Mr. Hart, that with the approval of the respective societies a joint committee should be formed, with the object of continuing the movement. Such a committee was accordingly nominated, and met at the National Health Society's rooms; a definite course of proceeding was resolved on, and a programme was sketched out. Various eminent persons known to be specially informed on the subject (not all connected with either Society) were asked to join the Committee."

Among those who have given most active assistance are Dr. Siemens, Capt. Douglas Galton, Mr. Atchison, and Col. Festing, R.E. ; but it is needless to say that all the eminent persons in art, literature, and science who have been asked to join have willingly given the valuable aid of their names, so that the Committee is a very representative one. The Exhibition includes a great variety of exhibits divided into the following sections :-

VOL. XXV.--No. 632
In Section $A$. will be found: Open coal-fire grates, stoves of all kinds, kitcheners, kitchen ranges, draughtregulators, base burners, and other appliances devised to prevent the liberation of smoke from bituminous coals or to consume anthracite and other smokeless fuel.

Section B.-Gas fircs, open grates and stoves, gas producers, and gas-heating apparatus of all kinds for domestic use.

Section C.-Appliances for heating rooms and buildings by hot air, hot water, and steam circulation.

Section D.-Gas engines, boiler furnaces, fire-bars, mechanical stokers, smoke-preventing furnace bridges, and other appliances for steam-engines and for general industrial purposes.

Section E.-Anthracite and other smokeless coals, bituminous and semi-bituminous coals, patent and other fuels.

Section F.-All foreign exhibits. Improvements in chimney flues, ventilating apparatus, and novel inventions for regulating temperature, \&c.

Buildings have been fitted up for the purpose of testing the efficiency of grates, stoves, and other appliances suited for domestic use ; and trials of various fuels and boiler appliances will also be conducted in the Exhibition Buildings, and at certain factories where facilities have been offered by the proprietors.

The Committee have secured the services of Mr. D. Kinnear Clark, M. Inst. C.E., to superintend the trials under the direction of the Executive Committee. In conjunction with Dr. Frankland, F.R.S., Prof. W. Chandler Roberts, F.R.S., has undertaken to make certain chemical tests in connection with the trials of fuel grates and stoves.

It is not unreasonable to expect that such an exhibition carried out under the direction of a Committee of Experts, which includes Prof. Abel, C.B., Royal Arsenal, Woolwich, A. T. Atchison, M.A., William R. E. Coles (Hon. Secretary), Col. E. R. Festing, R.E. (Science and Art Department, South Kensington), Capt. Douglas Galton, C.B., F.R.S., Prof. Edward Frankland, LL.D., F.R.S. (School of Mines, South Kensington), Sir Ughtred Kay-Shuttleworth, Bart., Dr. Siemens, F.R.S., LL.D., J. Lowry Whittle, Temple, will be of national value. It will tend directly to a better utilisation of coal and coal products, by determining practically and scientifically the means which are actually available for heating houses as at present (and as may be) constructed without producing smoke, as the Committee will be enabled to examine the subject generally and to report for public information upon the relative adaptability of the various coals and appliances to the requirements of every class of the community. Trustworthy information will be obtained upon which to base sufficient and equitable amendments of the existing laws regarding smoke; and the Committee will also ascertain and make known the comparative value of existing appliances for the utilisation of gas for the purpose of heating.

It must be admitted that for years past the air of London has steadily deteriorated, and that in London, which 150 years ago was famous for its roses, it is now impossible to get a rose to blossom or conifers to grow. Homely but practical evidence of the actinic influence of light, which is so essential to the health of plants 
and animals, was given by Mr. Ernest Hart at one of the many meetings which have been held on the subject, when he mentioned that wax manufacture had been, during the last twenty years, successively driven further and further from the centre of London. Ten years ago it was possible to bleach wax in the sunlight at Shepherd's Bush, but the factory was now removed to near Richmond, as it was found that the bleaching power of the sun for the greater part of the year was almost nullified by the pall of smoke which hangs over the metropolis. We shall not speak to-day of the various appliances of which we have as yet had but a hasty view, but it is only fair to say that there are shown at the Exhibition a number of grates, some of which, such as the new "Everitt" grate shown by Messrs. Barnard, Bishop, and Barnard; Mr. Crane's grate, shown by Deane and Co.; and in some respects the "Excelsior" grate of Mr. Archibald Smith, mark distinct advance. The possibility of consuming the smoke of bituminous coal in ordinary grates by forcing the draught of air and smoke downward through the fire before it is allowed to escape has been shown, as has also the facility with which hard anthracite smokeless coal will burn in open grates without any sort of blower or other such contrivance. In addition to these there is an extremely interesting series of exhibits of mechanical stokers, fire-bars for furnaces, a new gas-kiln which will be shown in operation, as well as Dr. Siemens' gas-regenerator. Some extremely good household stoves and fire-places are sent from Germany and Canada.

\section{DOUBLE-STARS}

Observations of Doubie-Stars. made at the United States Naval Observatory. By Asaph Hall, Professor of Mathematics, United States Navy, and Rear-Admiral Rodgers, U.S.N., Superintendent. (Washington : Government Printing Office, I88I.)

WE welcome another addition to our knowledge of the positions and distances of double stars. Prof. Asaph Hall has published a volume containing I6I4 observations of such stars made by him chiefly with the 26 -inch refractor at the Naval Observatory at Washington. The objects of the observations are two. Firstly, the detection of constant errors of observations by the measurements of double-stars from a selected list, and comparing such measures with those of other observers made as nearly as possible simultaneously; and, secondly, the measurements of double-stars generally.

The list of stars adopted is that prepared by Otto Struve, with a few additions of stars of greater distance. There are 30 stars in all, and 296 complete sets of measures of these have been made, each set consisting of four measures of position and two double measures of distance, except in cases where the stars exceed $3^{\prime \prime}$ in distance, when four were taken. The measures appear to be made with care, and the discrepancies are not greater than may be expected from night to night.

In connection with this subject Prof. Hall has applied a geometrical test to such observations by means of measures of the multiple stars $\Sigma 2703$ and $\Sigma 31 I$ and the stars in the trapezium of Orion. He says :-

"In the case of three stars A, B, C, if we take the origin of co-ordinates at $\mathrm{A}$, and observe the angles of position and the distances of $B$ and $C$ only, then these quantities are independent, and we may put their differentials equal to zero. But if we observe also the angle of position and the distance between $B$ and $C$ we have obtained more quantities than the geometrical conditions require, and must adjust the parts of the triangle by the method of least squares."

In the case of the triangles and the quadrilateral there appear to be no important systematic errors.

Prof. Hall gives a detailed account of the use of "rough circles" for setting the instrument on a star. These circles are the edges of the ordinary setting circles divided by lines of black paint on a white ground so as to be read without trouble, a method already adopted in some observatories in this country. He also describes the difficulties he has had with the driving clock, difficulties which are too often experienced with driving clocks of all kinds, and often arising from insufficiency of power and strength of parts to stand varying strains, and often dust and damp, which ordinary clocks do not generally experience. The dome, which is 42 feet in diameter, now turns with more difficulty, and if our experience is worth anything, such a difficulty once commenced will keep on fast increasing, and will very materially militate against the continued use of the instrument beneath it. The flexure of the telescope, which is 31 feet in length, and of the mounting, is small, and the working of the instrument very satisfactory.

A filar micrometer has been used for all the observations, and great care has been taken to test its accuracy, which is all that can be desired; but we note that the wires are illuminated by a lamp held by an assistant, a method somewhat primitive, as Prof. Hall says, and a waste of energy which might, we should have thought, have been useful elsewhere.

In all the ordinary observations four measures of position and two double measures of distances have been taken, and in all cases the head of the observer was kept in an upright or natural position. Owing to this we shall expect to find, on comparison of the list of test stars with others, a considerable error depending on the position of the stars with the horizon. No doubt practice has a great deal to do with it, but we have generally understood that the observations were more accurate and differed less inter se when made with line joining the eyes parallel to that joining the stars under observation.

Prof. Hall has included a good many very close stars, and it is to them that the large telescope can be most profitably turned, leaving the wider ones for the small instruments, with which they are well able to deal.

\section{OUR BOOK SHELF}

Zoological Atlas (including Comparative Anatomy), with Practical Directions and Explanatory Text for the Use of Students. Invertebrata. By D. M'Alpine. 249 Coloured Figures and Diagrams. (Edinburgh and London: W. and A. K. Johnston, 188r.)

THIS Atlas is prefaced by the following remarks:-“"In treating of the Invertebrata I have thought it advisable to depart slightly from the plan followed with the Vertebrata. There are five great divisions of Vertebrates recognised by naturalists, and a type or so of each was found to answer the purpose in view; but among Invertebrates the range of structure is immensely greater, and 